\title{
Social play of wild black-tufted-marmosets in the forest
}

\author{
Vanner Boere (iD - Marcelle de Castro Cavalheiro - Nadja Romera Süffert • Ita de Oliveira e Silva
}

V Boere (Corresponding author) - I Oliveira e Silva

Institute of the Humanities, Arts and Sciences of the Campus Jorge Amado, Federal University of Southern Bahia, 45604974, Itabuna, BA, Brazil.

email: vannerboere@uol.com.br

\section{Cavalheiro}

Post-graduate Program in Psychology, Institute of Psychology, University of Brasilia, 70910900, DF, Brazil.

\section{NR Süffert}

Post-graduate Program in Animal Biology, Institute of Biology, University of Brasilia, 70910900, DF, Brazil.

Received: May 22, 2019 • Accepted: August 02, 2019 • Published Online: August 29, 2019

\begin{abstract}
Locomotion can affect the performance (amount) of play behavior in marmosets due to high metabolic costs for primates. In addition, climatic conditions are known to limit the daily activities of marmosets. This study investigates the behavior of social play in wild marmosets and some limitations related to locomotion activities, daily travel and the seasonality of play. Two wild groups were observed with the focal method during the dry and wet seasons and all occurrences of play and locomotion were recorded. Adults played significantly less than juveniles, which played more than infants, and infants, more than the adults did. The reproductive couples played minimally. There was not a relationship between the distance traveled and the mean frequency of play. Nevertheless, all the age categories played significantly more in the wet season than the dry season. The independence to move and forage can explain higher play behavior of juveniles in relation to the infants. The adults and the reproductive couples, have higher energy costs in the group activities, such reproduction, compared to other age class, limiting their amount of play in relation to the juveniles and infants. We conclude that play behavior of juveniles black-tufted marmosets, does could not be impacted by daily locomotion unequivocally, but adults and infants, otherwise, are limited by other energetic costs and dependence to locomotion, respectively.
\end{abstract}

Keywords: Callithrix penicillata, behavior, Cerrados, ethology

\section{Introduction}

Play is the combination of behaviors expressed in conditions of relaxation, related to manipulation of the physical or social environment, with functions apparently out of the context of survival and reproduction (Burghardt 2005). Play behavior is classified as either solitary or social. Social play behavior involves dynamic contact and corresponds with other individuals of the same or other species (Burghardt 2005).

The function, the objectives and the origin of play remain unclear (Burghardt 2005). Play is probably one of the more enigmatic behaviors, principally because due to the lack of an act of consumption, it does not appear to have biological importance (Caro 1988), despite several functional theories to explain it (Burghardt 2005). For example, there are studies demonstrating that play is associated with increases of muscle growth and psychomotor development, to the encouragement of exploratory behavior, to an increase in socialization and a lifelong capacity to adapt to unexpected events (Spinka et al 2001). There are theories focusing an energetic balance to animals who play. One of the oldest and relatively wellaccepted theories is the Surplus Energy Theory (SET), formulated by Spencer in 1873 (Burghardt 2005). The principal argument of SET is that the animals have an "impulse to play" which is stronger when basic needs are met. Barber (1991) proposed that play behavior constitutes an adaptive mechanism for losing energy, preventing obesity and the energetic balance of diets with low protein intake.

No comprehensive explanation is sufficiently robust to explain play behavior in diverse species (Burghardt 2005). However, the play is widespread to all primate species and other taxa of animals. It is a consensus among researchers that animals with health disorders or in energetic stress play less than healthy and relaxed animals. The direction of an animal's play activity, therefore, depends on energy saving or energetic balance of other activities (Burghardt 2005).

Some studies of mammals demonstrate that intake and waste of metabolic energy are crucial to playing. For example, in meerkats (Suricata suricatta) play is associated with increased food availability (Sharpe et al 2002). Vervet monkeys (Cercopithecus aethiops) play substantially less during the dry season, a period of food shortage, compared to the wet season (Lee 1984). The common squirrel monkey 
(Saimiri sciureus), plays less in the dry season than the wet season, when an increased quantity of food resources is available (Stone 2008). Artificial food provisioning increased rates of play among Belding's ground squirrels Spermophilus beldingi (Nunes et al 1999).

Little is known about the factors that influence the play behavior of marmosets in natural environments (Yamamoto 1993). Only one long-term study was performed with Golden Lion Tamarins (Leontopithecus rosalia), a callitrichid like marmosets, in their natural environment (Oliveira et al 2003).

Black-tufted marmosets are widely distributed in the Cerrado, one of the ecosystems of Brazil, which is currently losing its biodiversity (Klink and Machado 2005). The Cerrado is subject to a seasonal regimen of extreme dryness and elevated rain precipitation (Klink and Machado 2005). For black-tufted marmosets, play can be a costly energy expenditure. Locomotion constitutes up to $70 \%$ of the activities of the C. penicillata groups (Miranda and Faria 2001) and seems to be an activity, which demands a high cost (Warren and Crompton 1998; Steudel-Numbers 2003). The groups of marmosets moved cohesively, rarely dispersing during their activities (Vilela and Faria 2004). The energetic costs of locomotion and play behavior could be different between age classes, affecting more the reproductive individuals.

The energy limitation caused by the lower food availability in the dry season (Miranda and Faria 2001; Vilela and Faria 2004), can inhibit play behavior in black-tufted marmosets when compared to the wet season. This effect would be more intense among reproductive individuals in which the nutritional supply and energetic necessities are unbalanced by the scarcity of food in the environment.

The objectives in this study were to describe the characteristics of play behavior in the natural environment of black-tufted marmosets and to verify that the frequency of this behavior can be adequately explained by a seasonal energy limitation (dry and wet seasons), considering daily movement and time of day. We have hypothesized that: 1) on days in which group movement is increased, the animals will play less to retain energy; 2) due to scarcity of foods with highest energy value, play will be less frequent in the dry season; and 3 ) the reproductive couples will play less than other age class, due to the high cost of reproduction.

\section{Materials and methods}

The study was performed at the Botanical Garden of Brasilia (S 1551'42', W 47'49'41', ), Federal District, Brazil, in an area of mesophytic, semi-deciduous forest in the Cerrado biome. The climate in the region presents two distinct, welldefined seasons, one dry (May to September) and one rainy (October to April).
There were two habituated groups of marmosets were observed, with the group sizes varying during the study (Table 1). Prior to the start of observations, the marmosets were captured in a trap of multiple entries, counted, identified, and marked. For better data analysis, the marmosets were classified in three age-class according to estimated ages and (Yamamoto 1993): infants (less than five months), juveniles (from five to 18 months) and adults (over 18 months). When not otherwise emphasized, the reproductive couples of the two groups were analyzed in the same class of adults due to the close to zero frequency of play behavior.

The observations occurred continuously between $6 \mathrm{~h}$ and $18 \mathrm{~h}$, for 8 months (June/2007 to February/2008), totaling $1150 \mathrm{~h}$. Both, play behavior, social or solitary, was recorded (Stevenson and Rylands 1988). All the play behavior occurred in situations of relaxation and never preceded agonistic behavior. When two or more animals disputed food with agonistic behavior (vocalization, piloerection, hits, and bites), it was not considered as play. Beyond the type of play, the number of individuals involved, and the start and end, times of the event were recorded. The name and the description of the observed behaviors are in Table 2 .

Table 1 Age composition of the Black-tufted marmosets groups observed in the Botanical Garden of Brasilia.

\begin{tabular}{lc}
\hline Composition & $\begin{array}{c}\text { Quantity of } \\
\text { individuals* }\end{array}$ \\
\hline Group 1 & $9-13$ \\
Adults (including a reproductive pair) & $7-10$ \\
Juveniles & $2-4$ \\
Infants & \\
Group 2 & 10 \\
Adults (including a reproductive pair) & $5-6$ \\
Juveniles & $4-6$ \\
Infants &
\end{tabular}

*Quantity of individuals could be changed due birth, change of age category, migration, death or disappearance.

The comparisons were performed by an inferential analysis, and hypotheses were tested by considering the ageclass, the average distance traveled daily, the time of day and the season of the year. A temporal approach to the distribution of play was also performed in each age-class category. To better understand the distribution of play behavior during the active period, three-time categories were created: the morning period, between $6 \mathrm{~h}$ and $10 \mathrm{~h}$; the intermediate period (from $10 \mathrm{~h}$ to $14 \mathrm{~h}$ ); and the afternoon period (from $14 \mathrm{~h}$ to $18 \mathrm{~h}$ ). Every 15 min, the number of visible animals and their positions were recorded, with the use of Global Positioning System instrument (eTrex; Garmin, USA). The geographic points 
captured by the GPS were analyzed with the help of the programs ARCGIS 9.2 and EXCEL.

The groups of marmosets moved cohesively, rarely dispersing during their activities (Vilela and Faria 2004). As locomotion constitutes up to $70 \%$ of the activities of the $C$. penicillata groups (Miranda and Faria 2001) and seems to be an activity, which demands a high cost (Warren and Crompton
1998; Steudel-Numbers 2003), we operationally defined the energetic cost of the daily activities as represented by the locomotion performed each day. To facilitate understanding of the analysis, we calculated the average distance traveled daily and classified the results into three levels: 1) from zero up to $552 \mathrm{~m}, 2$ ) from $553 \mathrm{~m}$ to $894 \mathrm{~m}$, and 3) over $894 \mathrm{~m}$.

Table 2 Behavioral activities observed from two groups of marmosets (C. penicillata) living in the Brasilia Botanic Garden (JBB), Brazil.

\begin{tabular}{ll}
\hline Behavior & Description \\
\hline Social play & Any play in which a marmoset interact with each other, without \\
& apparent objective. \\
Solitary play & Any play in which a marmoset performing alone, without apparent \\
& objective. \\
Agonistic behavior & Aggressive interactions between individuals such vocalization, \\
& grasping, biting, scratching, pushing \\
Travelling & Individual moving, running, jumping or walking \\
Inactive & Marmoset resting, sleeping, stationary position or awake, but not \\
& moving. \\
Other behavior & Any behavior performing by individuals such feeding, grooming, \\
& drinking water, vocalizing, mobbing and so on. \\
\hline
\end{tabular}

The temporal analyses, as well as others which followed (which are not emphasized to be contrary), were performed by applying a two-tailed paired t-test. The means of the frequencies of each behavior were considered by calculating the values separately by age category and group and considering the observation windows and total time of observation. To test the hypothesis, we initially made a correlation test (Pearson) between the marmosets' distance traveled daily with the amount of play. To comparing social play behavior among the age categories, we applied an ANOVA, followed by a Bonferroni test ad hoc.

The other analysis, to verify differences between age categories and to test the hypothesis through comparisons between the wet and dry seasons, was made by applying the two-tailed paired t-test, and the $\alpha \square 0.05$. The Brazilian legislation about ethical observations of wild animals had begun in 2012; the present study was performed between the years 2007 and 2008, precluding licenses to observe marmosets. However, all observations were with ethical standards and no harmful events for marmosets occurred during the study. It there was not obligatory legislation about noninvasive behavioral observation in that time, thus observers were ethical and legal during data collecting.

\section{Results}

The mean frequency of play of the two groups of marmosets did not differ ( $p>0.05$ ), for this, the analysis refers to the means of the two groups together. Of the 275 records of play (social and individual) between the marmosets, social behavior represented $93.1 \%$. Therefore, our analyses were directed toward social play. The interior of the forest was the preferred location for play $(60.2 \%)$, followed by the areas at the edges of the forest $(31.4 \%)$. The play occurred primarily in the lower stratum, between the soil and $1.5 \mathrm{~m}$ of height $(66.8 \%)$, followed by the medium and upper strata (18.2 and $15 \%$, respectively.) The soil composed of the substrate was most utilized (47.8\%), followed by the trunks and branches $(36.9 \%)$ and the tree canopy $(15.3 \%)$.

Comparing the age-class among themselves (Figure 1) by an ANOVA test, there were significant differences in the mean frequency of play $\left(F_{3,265}=167,92, p<0.001\right)$. The juveniles play more than the infants and those more than the adults do.

The temporal distribution of play was different for each age-class. The infants play significantly more in the intermediate period of the day than in the morning $\left(t_{265}=-3.93\right.$, $p<0.001)$ and afternoon $\left(t_{265}=2.09, p=0.04\right)$. It did not occur significant differences between the morning and afternoon $\left(t_{265}=-1.25, p=0.21\right)$. As with the infants, the juveniles play significantly more during the intermediate period of the day, in relation to the morning period $\left(t_{265}=-2.29, p=0.02\right)$. There were no significant differences between the intermediate and afternoon periods $\left(t_{265}=1.07, p=0.29\right)$ and between the morning and the afternoon $\left(t_{265}=-1.12, p=0.26\right)$. For adults, 
significant differences were not observed in the periods cited above (morning and intermediate: $t_{265}=1.46, p=0.14$; afternoon and intermediate: $t_{265}=-1.89, p=0.06$ and morning and afternoon: $t_{265}=-0.34, p=0.73$ ).

Groups 1 and 2 did not differ for locomotion $\left(t_{265}=\right.$ 1.173, $p=0.25$ ). A strong correlation between the distance traveled daily and the frequency of play of the different age groups (infants: $\mathrm{r}=0.36, \mathrm{p}=0.06$; juveniles $=\mathrm{r}=0.23, \mathrm{p}=0.23$; adults: $\mathrm{r}=0.12, \mathrm{p}=0.53$; reproductive couples: $\mathrm{r}=0.31, \mathrm{p}=0.10$ ), was not observed. Thus, it is suggesting there is no priority dependence between energy expenditures for one activity or another. The frequency of play was significantly less in the dry season in relation to the wet season for juveniles $\left(t_{265}=-\right.$ 3.6, $p=0.001)$ and adults $\left(t_{265}=-3.4, p=0.001\right)$, but not for the infants $\left(t_{265}=6.8, p=0.001\right)$.

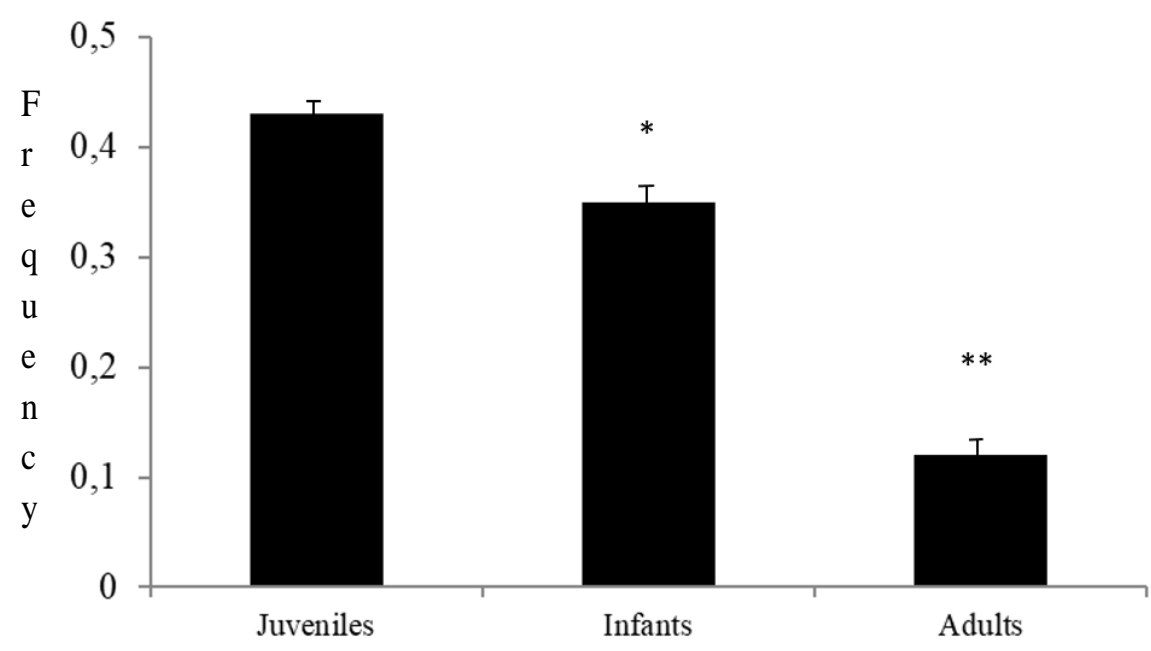

Figure 1 Age categories differences of social play behavior in two wild groups of Black-tufted marmosets. There were significant differences in each category. The juveniles play more than the infants (*Bonferroni test, $\mathrm{p}<0.01)$, and those more than the adults $(* * B$ onferroni test, $\mathrm{p}<$ 0.001).

\section{Discussion}

Together, the results were not clear-cut to prove the hypothesis that play behavior depends on energy saving in black-tufted marmosets. While the results obtained of the analysis of play behavior of the marmosets by age-class, time of day or seasonal distribution could be explained by energetic limitations, the relation between the cost of locomotion and the frequency of play did not prove the hypothesis that energy is a limiting factor.

The energy cost of the locomotion can be estimated from the distance traveled and other variables such as the type of locomotion (bipedal, quadrupedal, saltatory or suspensory), climatic conditions and the weight of the individual (SteudelNumbers 2003). Using distance traveled as an estimate of the energy cost for the entire group suggests that there is not a relationship between spending energy and playing. In the analysis of each age category, the relation between the distance traveled and play suggests discrepancies between the individuals. Therefore, it suggests that daily distance traveled does not a good proxy to estimate energy cost regarding play behavior in black-tufted marmosets.

Despite these limitations, the cost of locomotion for the group, independent of the age-class, is not related to the frequency of play. Part of the explanation is because the age class differs in the frequency of play. The juveniles and the infants play more than the adults (including the reproductive couples) do, and this result may have counterbalanced the correlation with the locomotion. The infants are dependent on older animals to move long distances in the forest, positioning on the back of older marmosets, especially the reproductive males (Locke-Hayden and Chalmers 1983). Mainly the adult's care the infants almost time in their natural environment, until two months of life (Stevenson and Rylands 1988).

The adults have additional energy costs (Yamamoto, 1993) not estimated in the present study. Adults generally involve themselves in the defense against other groups, watch for predators and help with parental care (cleaning and feeding) of the infants. The reproductive females who are breastfeeding can gestate a new pair of infants during this phase (Tardiff et al 2001), which is one energy cost limit of marmosets (Goldizen 1990). These limitations do not occur in juveniles and in the infants. Juveniles can take care of infants, but the contribution is small when compared to the adults (Bales et al 2000; Yamamoto et al 2008). Therefore, it seems plausible that there is excess energy for play in juveniles and infants, favoring the spending of this "surplus" energy in play behavior.

Infants are dependent on adults and juveniles members of the marmoset group. Despite this dependence, there is no correlation between distance traveled daily and the frequency 
of play behavior in the infants. Nevertheless, we analyzed the juvenile and adult categories and observed that there is a difference in the frequency of play, which conforms to the distance traveled daily. The amount of play decreases when the marmosets travel shorter distances and increases when the marmosets travel longer distances. This apparent energy paradox can be explained by a lower general disposition to activities; including both locomotion and play in these two age categories, during the rainy season. This also occurs in the play behavior of gelada baboons (Theropithecus gelada) (Barret et al 1992), which lowers its activity in response to sudden storms in the wet season. The activity of marmosets is reduced when it rains, as they go into the trees earlier to rest or become quiet during the storm (Alonso and Langguth 1989; Vilela and Faria 2004; Silva 2008).

We observed that the infants and the juveniles concentrated on play behavior in the intermediate period of the day, between 10 and $14 \mathrm{~h}$. That period is described as a phase of rest and of lower activity of marmoset groups (Miranda and Faria 2001), but not for juveniles and infants of this study. The results here demonstrate that at least part of the group uses that period for the increased play behavior, particularly in relation to the first hours of the morning.

Previous studies have demonstrated that early morning marmosets forage intensely (Miranda and Faria 2001; Vilela and Faria 2004). That seems to be the case with these studied groups as well. Silva (2008) observed the feeding behavior of these same marmosets at the same time of the present study, and described that there is a concentration of foraging activities and eating in the first hours of the morning. In the intermediate phase of the day, the animals have presumably already had sufficient intake of nutrients and energy. Due to the early morning intake of nutrients, it is understandable why juveniles and infants concentrate their play in the intermediate phase of the day in relation to the first period of the morning. On the other hand, adults are motivated to rest and does not play at all, maybe due the vigilant behavior to predators (Rylands and Faria, 1993).

It seems essential then that the first forage is for an ingestion of nutrients, and play occurs afterward. This may explain why the adults tended to play in the afternoon period, when there is an accumulation of energy from the foods ingested in the two previous periods (between 6 and 10h; and between 10 and 14h). Comparatively, in the species of callitrichid, the golden lion tamarin, social play in the intermediate phase of the day was also more frequent but on a small scale as part of the daily activities (Oliveira et al 2003). Evidence that play may be restricted to golden lion tamarins due to energy limitations has not yet been observed.

Our hypothesis is that in shorter distances the marmosets play more and vice-versa. The result suggests that in shorter distances traveled, the juveniles and the adults play less in relation to the mean or longer distances. The play did not differ in either mean or longer distances traveled, suggesting that the spent energy in locomotion does not appear to be limiting the amount of play in juvenile and adult marmosets.

Indeed, there are some studies suggesting that the play may not have a great impact on the energy costs of some species. In mice (Rattus novergicus), play behavior can represent an energy cost of 10\% (Sivyi and Atrens 1992), with a lower value in infant animals which have not yet reproduced. In domestic cat (Felis catus) play seems to have an insignificant energetic cost (4\%) on the daily metabolism (Martin 1984). A study with infant cheetahs (Acinonyx jubatus) demonstrated that play may not have a high enough energy cost to affect other activities (Caro, 995). Despite the energetic limitations of each species, the energy cost of play can be insignificant for infants and juveniles, but be substantial for adult marmosets.

Our study does not rule out other proximal and distal causes of the play behavior in marmosets, such acquisition of skillfulness (Chalmers and Locke-Haydon, 1984), reducing stress (Norscia and Palagi, 2011), hormonal condition (Birnie et al 2012) and expression of neurotransmitter (Trezza et al 2010). However, our focus was the energetic cost in natural conditions, using distance traveled, seasonality and other socio-ecological conditions such age class and reproductive status, considering many studies which well-definite roles e pressures on marmosets them (Rylands and Faria, 1993).

In general, these results suggest that there is not dependence between the energy costs of locomotion and the mean frequency of play in black-tufted marmosets, negating our first hypothesis. However, there are evidence to consider correct our second and third hypothesis: due to the scarcity of foods with a highest energy value, the play will be less frequent in the dry season, and the reproductive couples will play less than other age class. To our knowledge, the present study is the first on black-tufted marmosets play behavior in their natural environment, through an energetic perspective.

\section{Acknowledgements}

We are grateful to Mariana Queiroz and Samara Rinco de Granca for the field assistance. We are in debt with the staff of the Botanical Garden of Brasilia for the help and permission to study the marmosets.

\section{References}

Alonso C, Langguth A (1989) Ecologia e comportamento de Callithrix jacchus (Primates: Callitrichidae) numa ilha de floresta Atlântica. Revista Nordestina de Biologia 6:105-137.

Andrews MW, Rosenblum LA (1993) Assessment of attachment in differentially reared infant monkeys (Macaca radiata): Response to separation and a novel environment. Journal of Comparative Psychology 107:84-90. 
Bales K, Dietz J, Baker A, Miller K, Tardif SD (2000) Effects of allocare-givers on fitness of infants and parents in Callitrichid Primates. Folia Primatologica 71:27-38.

Barret L, Dunbar RIM, Dunbar P (1992) Environmental influences on play behaviour in immature gelada baboons. Animal Behavior 44:111-115.

Birnie AK, Hendricks SE, Smith AS, Milam R, French JA (2012) Maternal gestational androgens are associated with decreased juvenile play in white-faced marmosets (Callithrix geoffroyi). Hormones and Behavior, 62:136-145.

Burghardt GM (2005) The genesis of animal play: Testing the limits. MIT Press, Cambridge.

Caro, T. M. 1988. Adaptive significance of play: Are we getting closer? Trends Ecology Evolution 3:50-54.

Caro TM (1995) Short-term costs and correlates of play in cheetahs. Animal Behavior 49:333-345.

Chalmers NR, Locke-Haydon J (1984) Correlations among measures of playfulness and skillfulness in captive common marmosets (Callithrix jacchus jacchus). Developmental Psychobiology 17:191208.

Goldizen AW (1990) A comparative perspective on the evolution of tamarin and marmoset social systems. International Journal of Primatology 11:63-83.

Klink CA, Machado RB (2005).Conservation of Brazilian Cerrado. Conservation Biology 19:707-713.

Lee PC (1984) Ecological constraints on the social development of Vervet monkeys. Behaviour 91:245-262.

Locke-Haydon J, Chalmers NR (1983) The development of infantcaregiver relationships in captive common marmosets (Callithrix jacchus). International Journal of Primatology 4:63-81.

Martin P (1984) The time and energy costs of play behavior in the cat. Zeitschrift Tierpsychologie 64:298-312.

Miranda GHB, Faria DS (2001) Ecological aspects of blackpincelled mamorset (Callithrix penicillata) in the cerradão and dense cerrado of Brazilian Central Plateau. Brazilian Journal of Biology 61:397-404.

Norscia I, Palagi E (2011) When play is a family business: adult play, hierarchy, and possible stress reduction in common marmosets. Primates 52:101-104

Nunes S, Muecke E-M, Anthony JA, Batterbee AS (1999) Endocrine and energetic mediation of play behavior in free-living Belding's ground squirrels. Hormones and Behavior 36:153-165.

Oliveira CR, Ruiz-Miranda CR, Kleiman DG, Beck BB (2003) Play behavior in juvenile golden lion tamarins (Callitrichidae: primates): organization in relation to costs. Ethology 109:593-612.
Rylands AB, Faria DS (1993) Habitats, feeding, and home range size in the genus Callithrix, p. 262-272. In: A.B. Rylands (Ed). Marmosets and Tamarins (Systematics, Behaviour, and Ecology). New York, Oxford Univ. Press, 396p

Sharpe LL, Clutton-Brock TH, Brotherton PNM, Cameron EZ, Cherry MI (2002) Experimental provisioning increases play in freeranging meerkats. Animal Behavior 64:113-121.

Silva IO (2008) Socialidade e acesso a recursos alimentares por fêmeas de saguis (Callithrix penicillata) em grupos em ambiente natural. Doctoral thesis, Postgraduate program in Animal Biology, University of Brasilia, Brazil.

Siviy SM, Atrens DM (1992) The energetic costs of rough-andtumble play in the juvenile rat. Developmental Psychobiology 25:137-148.

Spinka M, Newberry RC, Bekoff M (2001) Mammalian play: training for the unexpected. The Quarter Review of Biology 76:141168.

Steudel-Numbers KL (2003) The energetic cost of locomotion: humans and primates compared to generalized endotherms. Journal of Human Evolution 44:255-262.

Stevenson MF, Rylands AB (1988) The marmosets, genus Callithrix. In: Mittermeier, RA Mittermeier RA, Rylands AB, Coimbra-Filho AF, da Fonseca GAB (eds.) Ecology and Behavior of Neotropical Primates, 2nd vol. WWF, New York, pp 131-222.

Tardif SD, Power M, Oftedal OT, Power RA, Layne DG (2001). Lactation, maternal behavior and infant growth in common marmoset monkeys (Callithrix jacchus): effects of maternal size and litter size. Behavioral Ecology Sociobiology 51:17-25.

Trezza V, Baarendse PJJ, Vanderschuren LJMJ (2010). The pleasures of play: pharmacological insights into social reward mechanisms. Trends Pharmacology and Science.31:463-469.

Vilela SL, Faria DS (2004). Seasonality of the activity pattern of Callithrix penicillata (Primates, Callitrichidae) in the cerrado (scrub savanna vegetation). Brazilian Journal of Biology 64:363-370.

Yamamoto ME, Albuquerque FS, Lopes NA, Ferreira ES (2008). Differential infant carrying in captive and wild common marmosets (Callithrix jacchus). Acta Ethologica 11:95-99.

Yamamoto ME (1993). From dependence to sexual maturity: The behavioural ontogeny.

of Callitrichidae. In: Rylands AB (ed.) Marmosets and Tamarins. Systematics, Behaviour and Ecology. Oxford University Press, Oxford, pp. 235-254.

Warren RD, Crompton RH (1998). Diet, body size and the energy costs of locomotion in saltatory primates. Folia Primatologica 69:86100. 